\title{
Litter gender composition and sex affect maternal behavior and DNA methylation levels of the Oprm1 gene in rat offspring
}

\author{
Yanli Hao ${ }^{1,2}$, Wen Huang 1,2, David A. Nielsen ${ }^{1,2}$ and Therese A. Kosten ${ }^{1,2 *}$ \\ 1 Menninger Department of Psychiatry and Behavioral Sciences, Baylor College of Medicine, Houston, TX, USA \\ 2 Michael E Debakey Veterans Administration Medical Center, Houston, TX, USA
}

Edited by:

Josephine Johns, University of North

Carolina at Chapel Hill, USA

Reviewed by:

Elizabeth Mccone Byrnes, Tufts

University Cummings School of

Veterinary Medicine, USA

Lisa Schrott, LSU Health Sciences

Center-Shreveport, USA

*Correspondence:

Therese A. Kosten, Menninger

Department of Psychiatry and

Behavioral Sciences, Baylor College of

Medicine, 2002 Holcombe Boulevard,

Houston, TX77030, USA.

e-mail: tkosten@bcm.edu
The mu-opioid receptor is encoded by the Oprm1 gene and contributes to mother-infant behaviors. Rodent dams lick male pups more than female pups in the anogenital region. This behavior is linked to stress responsivity in the offspring that may be mediated by epigenetic changes. We hypothesized that maternal behavior may affect DNA methylation levels of the Oprm 1 gene and show sex differences. To further explore sex differences in mother-pup behaviors and DNA methylation levels, we altered the litter gender composition (LGC) of rats. Litters were culled to eight all male, all female, or four male/four female pups on postnatal (PN) day 1. On PN4, 7, and 10, a dam was placed in a test cage with a pup for a 10-min period. Latency to pup contact was determined as were times spent licking the anogenital and other body regions of the pup. Frequencies of other behaviors were tabulated. On PN35, samples from various brain regions were obtained. DNA methylation at specific $\mathrm{CpG}$ sites in the Oprm 1 promoter region were measured by direct sequencing of bisulfite-treated DNA. LGC and sex interacted with day for latency to pup contact. Latencies were longest on PN4 for single-sex males and on PN10 for single-sex females. Dams licked male pups more than female pups in both the anogenital and other body areas. Sex differences were seen in other behaviors. LGC altered DNA methylation at specific CpG's of Oprm1 in hippocampus with higher levels in single-sex rats. In nucleus accumbens, single-sex males showed hypermethylation levels, a trend seen in caudate-putamen. Results confirm and extend sex differences in maternal care with modest LGC effects. That both LGC and sex have enduring effects on DNA methylation of the Oprm 1 gene in brain regions associated with addiction, stress regulation, motivation, and cognition may suggest one factor that contributes to gender differences in these behaviors.

Keywords: mu-opioid, epigenetics, CREB, female, attachment behavior

\section{INTRODUCTION}

Males and females differ in incidences of several behavioral disorders. Autism, antisocial personality and addictive disorders are more common in men, whereas depressive and anxiety disorders are more common in women (Fombonne, 2003; Grant et al., 2009; Vigod and Stewart, 2009). Although alcoholism and drug addiction are more common in men, women progress more quickly from initial use to abuse and dependence (Greenfield et al., 2010). Further, women are just as likely as men to use or abuse prescription opiate drugs (McCabe et al., 2005). In addition, stress exposure, that can precipitate behavioral disorders (Sinha, 2001; Caspi et al., 2003), has greater effects in women than men (Kudielka and Kirschbaum, 2005).

Stress exposure activates the hypothalamic-pituitary-adrenal (HPA) axis. A cascade of events occurs in which corticotrophinreleasing factor release from the paraventricular nucleus of the hypothalamus stimulates the pituitary to cleave proopiomelanocortin into adrenocorticotropic hormone $(\mathrm{ACTH})$ and the endogenous opioid, beta-endorphin as well as other peptides. ACTH is released into the blood stream causing secretion of the glucocorticoid, corticosterone, from the adrenal cortex (Rivier and Plotsky, 1986; Dunn and Berridge, 1990). Beta-endorphins interact with opioid receptors, particularly mu-type receptors, both centrally and in the periphery.
Sex differences are seen in stress responsivity and in the behavioral responses to opioids in rats. Female rats show larger stress hormone and behavioral responses to foot shock compared to male rats (Beatty and Beatty, 1970; Kosten et al., 2006) and greater analgesic responses to various opioids (Craft, 2003). There are also sex differences in the reinforcing effects of opioids. In most cases, female rats show greater operant self-administration (Lynch and Carroll, 1999; Carroll et al., 2002; Cicero et al., 2003) and place conditioning effects of opioids (Cicero et al., 2000) although not in all cases (Stewart et al., 1996). These sex differences may reflect activational or organization effects of gonadal hormones (Kitay, 1961; Viau and Meaney, 1991; Cicero et al., 2002; McCormick et al., 2002) and may relate to the higher density or binding of mu-opioid receptors in female rats and humans relative to males (Hammer, 1990; Zubieta et al., 1999).

Mu-opioid receptors are involved with mother-infant attachment (Nelson and Panksepp, 1998). Administration of morphine or other opioid agonists reduces the rat pups' ultrasonic vocalizations (USV; Kehoe and Blass, 1986; Carden et al., 1991) provoked by isolation from the dam and decrease vocalizations of the infant nonhuman primate after separation from its mother (Kalin et al., 1988). Although this neuropharmacological relationship was called into question (Winslow and Insel, 1991), recent molecular genetic work 
confirms the role of mu-opioid receptors in attachment behavior in both rodents and non-human primates. After separation from their dam, mice lacking the mu-opioid receptor gene, Oprm1, emit fewer USVs (Moles et al., 2004). Maternal separation-induced vocalizations in infant primates associates with a polymorphism of the OPRM1 gene (Barr et al., 2008). These studies not only reaffirm the role of the mu-opioid receptor in mother-infant attachment but also suggest a genetic basis for variations in maternal behaviors. However, it is possible that manipulating maternal behavior may affect this gene expression.

Emerging evidence suggests that changes in gene expression resulting in stable phenotypic alterations can be induced by early life manipulations. Genes may be silenced during development through DNA methylation (Jones and Taylor, 1980). Once a methyl group is attached to DNA, transcriptional factors cannot access the gene and it is silenced (Razin, 1998). The methylation status of the $\mathrm{Gr} 1_{7}$ promoter in hippocampus was found to be associated with variations in the maternal behavior of anogenital licking and binding of the transcription factor nerve growth factor-inducible factor A (Ngfi-a) in the offspring (Champagne et al., 2003; Weaver et al., 2004). Further, this altered gene expression associates with hormonal and behavioral responses to stress in the adult offspring. Other early life manipulations, such as limited nesting material or high-fat diet, affect DNA methylation of other genes (Roth et al., 2009; Vucetic et al., 2010, 2011). Thus, the structure of DNA can be modified by early life manipulations resulting in a change in the phenotype of the offspring.

Maternal behavior differs by sex of the pup. Dams spend more time in active nursing, nest-building, and licking male pups in the anogenital region compared to female pups (Moore and Morelli, 1979; Richmond and Sachs, 1984; Moore and Chadwick-Dias, 1986; Alleva et al., 1989; Cirulli et al., 1997). Licking the anogenital area stimulates urine and feces elimination of the pup (Gubernick and Alberts, 1983) and helps suppress HPA activity (Stanton et al., 1988; Suchecki et al., 1995; Levine, 2001). Suppression of the HPA axis and the ensuing increase in corticosterone levels may be particularly important for a pup because it can prevent glucocorticoid and mineralocorticoid receptor stimulation in hippocampus. Stimulation of these receptors could have deleterious effects (Sapolsky and Meaney, 1986) on the developing hippocampus (Rice and Barone, 2000; Dumas, 2005), a region that is important for modulating stress responses (Chrousos and Gold, 1992), and also for learning, memory (Scoville and Milner, 1957; McGaugh, 2000), and emotion (Gray, 1982; McHugh et al., 2004; Barkus et al., 2010).

The sex-dependent effects of maternal behavior can be altered by modifying the litter gender composition (LGC) in which offspring of single-sex litters are compared to offspring of mixed-sex litters (Moore and Morelli, 1979; Alleva et al., 1989; Cirulli et al., 1997; Laviola et al., 1999). LGC affects various behaviors of the offspring including analgesic responses to morphine in juvenile male mice with mixed-sex males showing longer response latencies than single-sex males (Alleva et al., 1986). In the present study, we further examined if LGC affects the sex dependency of motherpup behaviors assessed after a short separation. At 7-weeks of age (PN35), brain tissue samples were obtained from hippocampus, nucleus accumbens (NAc), and other areas to test for DNA methylation levels of the Oprm1 gene.

\section{MATERIALS AND METHODS SUBJECTS AND HOUSING}

Male and female rats (Sprague-Dawley, Charles River, MA, USA) were housed in polypropylene cages in a temperature- and humidity-controlled vivarium maintained on a 12:12 light/dark cycle (lights on at 0700 hours). Food and water were available ad libitum. All procedures were approved by the Baylor College of Medicine Institutional Animal Care and Use Committee (IACUC) in strict accordance with guidelines set forth by the National Institutes of Health.

Sets of one male and two females were paired for breeding. When pregnancy was suspected, females were transferred to individual cages. Litters found before 1700 hours were considered born on that day (Postnatal Day 0; PN0). On PN1, litters were weighed and culled to eight pups. Pups that were not needed for the study were euthanized humanely at this time.

\section{GROUPS}

Litter gender composition was manipulated by cross-fostering litters to either single-sex (male or female) or mixed-sex (half male and half female). A total of 42 litters were studied including 10 single male, 12 single female, and 20 mixed-sex litters. Only one pup per litter was sampled. Half of the mixed-sex litters were used to sample a male pup and the other half were used to study the female pup in the mother-pup behavior study. However, in the DNA methylation study, tissue samples were obtained from one male and one female in each of the mixed-sex litters (i.e., $n$ 's $=20$ ) and one pup was chosen from each single-sex litter. One of the single male litters was lost so for this analysis, there were nine single male litters.

\section{MOTHER-PUP BEHAVIOR PROCEDURE}

Ratings of mother-pup behaviors were performed between 0900 and 1200 in the following manner. The dam was removed from the home cage and placed in a glass observation tank (13' $\mathrm{H} \times 20^{\prime} \mathrm{L} \times 16.5^{\prime} \mathrm{W}$ ) contained in a sound-attenuating cubicle equipped with a video camera for 30-min. One of her pups was then removed from the home cage and placed in the observation tank for 10-min. The remaining pups in the litter were kept in the home cage and placed under a heat lamp during the observation period. Video was recorded as soon as the pup was placed in the tank. Video files were coded so that the rater would be blind to litter condition, sex of pup, and postnatal day. This procedure was performed at three time points, PN4, PN7, and PN10, to allow for ontogenetic effects based on previous work (Richmond and Sachs, 1984). The pup was weighed prior to placing it in the observation tank with the exception of the first four litters (one from each condition).

Video files were rated by tabulating the frequency of various behaviors using a time sampling procedure. The rater listened to a recording that beeped every $30-$ s at which time she would record which behaviors were occurring. The behaviors tabulated are listed and defined in Table 1. Data on frequencies of each behavior were summed across the entire 10-min session on each of the three test days (PN4, PN7, PN10) in order to examine the effects of LGC and sex on each behavior. In addition to rating these behaviors, latency to the initial contact with the pup and the total times spent licking 


\begin{tabular}{|c|c|c|}
\hline Variable & Definition & Analysis \\
\hline Carry & Dam picks up pup by dorsal skin with her incisors and carries it to another place & Rate frequency \\
\hline Blanket nursing & $\begin{array}{l}\text { Dam engages in blanket nursing in which she is over the pup in a bilaterally symmetrical } \\
\text { manner and is relatively immobile with or without limb support }\end{array}$ & Rate frequency \\
\hline Rearing & Dam stands on hindlimbs without touching cage wall & Rate frequency \\
\hline Grooming & Dam licks, scratches, or chews any part of own body & Rate frequency \\
\hline Latency & Time it takes for the dam to touch the pup with forepaws or nose & Time (s) \\
\hline Anogenital licking & Time dam spends licking the pup's anogenital region exclusively & Time (s) \\
\hline Body licking & Time dam spends licking the pup's body except for anogenital region & Time (s) \\
\hline
\end{tabular}

the anogenital region and other parts of the body were recorded in seconds over the entire 10-min session each day. These behaviors are defined in Table 1.

\section{DNA METHYLATION}

Tissue samples of hippocampus, NAc, caudate-putamen (CP), and cerebellum were obtained from one rat per condition and sex on PN35 with the purpose of measuring DNA methylation levels of the Oprm1 gene. We chose this age because it allows enough post-weaning time to test if potential effects on DNA methylation are long-lasting. Rats were anesthetized (Ketamine) then decapitated. Tissue samples were rapidly dissected in slices of 1.5-mm using a Rodent Brain Matrix (RBM-4000C, ASI Instruments, Warren, MI, USA) and immediately placed on dry ice. Samples were stored at $-80^{\circ} \mathrm{C}$ until they were processed for DNA. DNA was isolated from the tissue using the Gentra Purgene DNA isolation method (Qiagen, Valencia, CA, USA) according to manufacturer's protocol.

DNA methylation levels were quantified using the methods detailed previously (Nielsen et al., 2009). Nucleotide sequence of the rat Oprm1 gene promoter region [chr1:37533440-37536440, Rat Nov. 2004 (Baylor 3.4/rn4)] was downloaded from the UCSC Genome Browser website (genome.ucsc.edu). The predicted bisulfite-treated sequence was determined using the Methyl Primer Express 1.0 software (Applied Biosystems, Foster City, CA, USA) and exported to Vector NTI Advance 11 (Invitrogen, Carlsbad, CA, USA). Primers for amplification of the bisulfite-treated DNA were designed with Vector NTI Advance 11, and synthesized (Midland Reagent Co., Midland, TX, USA).

To determine percent cytosine methylation, genomic DNA (300 ng) was sodium bisulfite-treated using the EZ-96 DNA Methylation Kit D5004 (Zymo Research, Orange, CA, USA) and amplified with primers M-RATOPRM1-1F (5'-TTTTGGTTTTATTAGGGTTG-3') and M-RATOPRM1-1R (5'-ACCAAAAACCAAATACTAAA-3'). Amplification was performed with $2 \mu \mathrm{l}$ bisulfite-treated DNA, $1 \mu \mathrm{M}$ of each primer, $200 \mu \mathrm{M}$ each of dATP, dCTP, dGTP, and TTP, $18 \mathrm{mM}$ ammonium sulfate, $2 \mathrm{mM} \mathrm{MgSO}_{4}, 0.5$ units Platinum ${ }^{\circledast}$ Taq DNA Polymerase High Fidelity (Invitrogen), and $60 \mathrm{mM}$ Tris-SO $\mathrm{SO}_{4}(\mathrm{pH} 8.9)$ in $25 \mu \mathrm{l}$. Amplification consisted of $1 \mathrm{~min}$ at $94^{\circ} \mathrm{C}, 3$ cycles of $15 \mathrm{~s}$ at $94^{\circ} \mathrm{C}$, $15 \mathrm{~s}$ at $55^{\circ} \mathrm{C}$, and $15 \mathrm{~s}$ at $68^{\circ} \mathrm{C}, 3$ cycles of $15 \mathrm{~s}$ at $94^{\circ} \mathrm{C}, 15 \mathrm{~s}$ at $52^{\circ} \mathrm{C}$, and $15 \mathrm{~s}$ at $68^{\circ} \mathrm{C}, 3 \mathrm{cycles}$ of $15 \mathrm{~s}$ at $94^{\circ} \mathrm{C}, 15 \mathrm{~s}$ at $49^{\circ} \mathrm{C}$, and $15 \mathrm{~s}$ at $68^{\circ} \mathrm{C}, 3$ cycles of $15 \mathrm{~s}$ at $94^{\circ} \mathrm{C}, 15 \mathrm{~s}$ at $46^{\circ} \mathrm{C}$, and $15 \mathrm{~s}$ at $68^{\circ} \mathrm{C}, 3 \mathrm{cycles}$ of $15 \mathrm{~s}$ at $94^{\circ} \mathrm{C}, 15 \mathrm{~s}$ at $43^{\circ} \mathrm{C}$, and $15 \mathrm{~s}$ at $68^{\circ} \mathrm{C}$, followed by a final elongation step at $68^{\circ} \mathrm{C}$ for $7 \mathrm{~min}$. Unincorporated nucleotides and primers were degraded by mixing $4 \mu \mathrm{l}$ of the final PCR reaction mixture with $1 \mu \mathrm{l}$ ExoSAP-IT (USB Corp., Cleveland, OH, USA) followed by incubation at $37^{\circ} \mathrm{C}$ for $30 \mathrm{~min}$ and $80^{\circ} \mathrm{C}$ for $15 \mathrm{~min}$. For sequencing, $1 \mu \mathrm{l}$ ExoSAP-IT-treated DNA was added to $11 \mu \mathrm{l} 8 \mathrm{pM}$ primer M-RATOPRM1-1F or M-RATOPRM1-1R. Sequencing was performed at GENEWIZ, Inc. (South Plainfield, NJ, USA) on an ABI 3730 XL sequencer using the ABI 3730POP7SR basecaller (Applied Biosystems). Trace files (.ab1) were analyzed using the ESME version 3.2.1 software from Epigenomics AG (Berlin, Germany; Lewin et al., 2004). Nucleotides are numbered relative to the A of the ATG of the Oprm 1 translation start site. The rat Oprm1 promoter region was analyzed for predicted transcription factor binding sites using TESS: Transcription Element Search System (Schug and Overton, 1977).

\section{DATA ANALYSIS}

The sums of the frequencies of each behavior on each day were analyzed in separate $2 \times 2 \times 3$ ANOVAs using litter as the experimental unit for analysis. This represents the between group factors of LGC (single-sex or mixed-sex litter) and sex (male or female) with repeated measures on postnatal day. Total times (seconds) spent licking (anogenital region and other body regions) were analyzed in the same manner. Body weight was analyzed using weight on PN1 as a co-variate although there was no difference in body weights across litter conditions on this day. DNA methylation levels were analyzed using separate $2 \times 2 \times 7$ ANOVAs by brain region. This represents the same between group factors with repeated measure on CpG site. Post hoc univariate tests were used to follow-up on significant effects. Significance was set at 0.05 and trend toward significance was set at 0.10 .

\section{RESULTS}

\section{BODY WEIGHT}

Body weight was measured on PN1, 4, 7, and 10. These data are shown in Figure 1. As seen in the figure, body weight increased over days as supported by the Day effect, $F(3,114)=1,144.48 ; P<0.0001$. Neither LGC nor Sex affected body weight $\left(P^{\prime} s>0.10\right)$. 


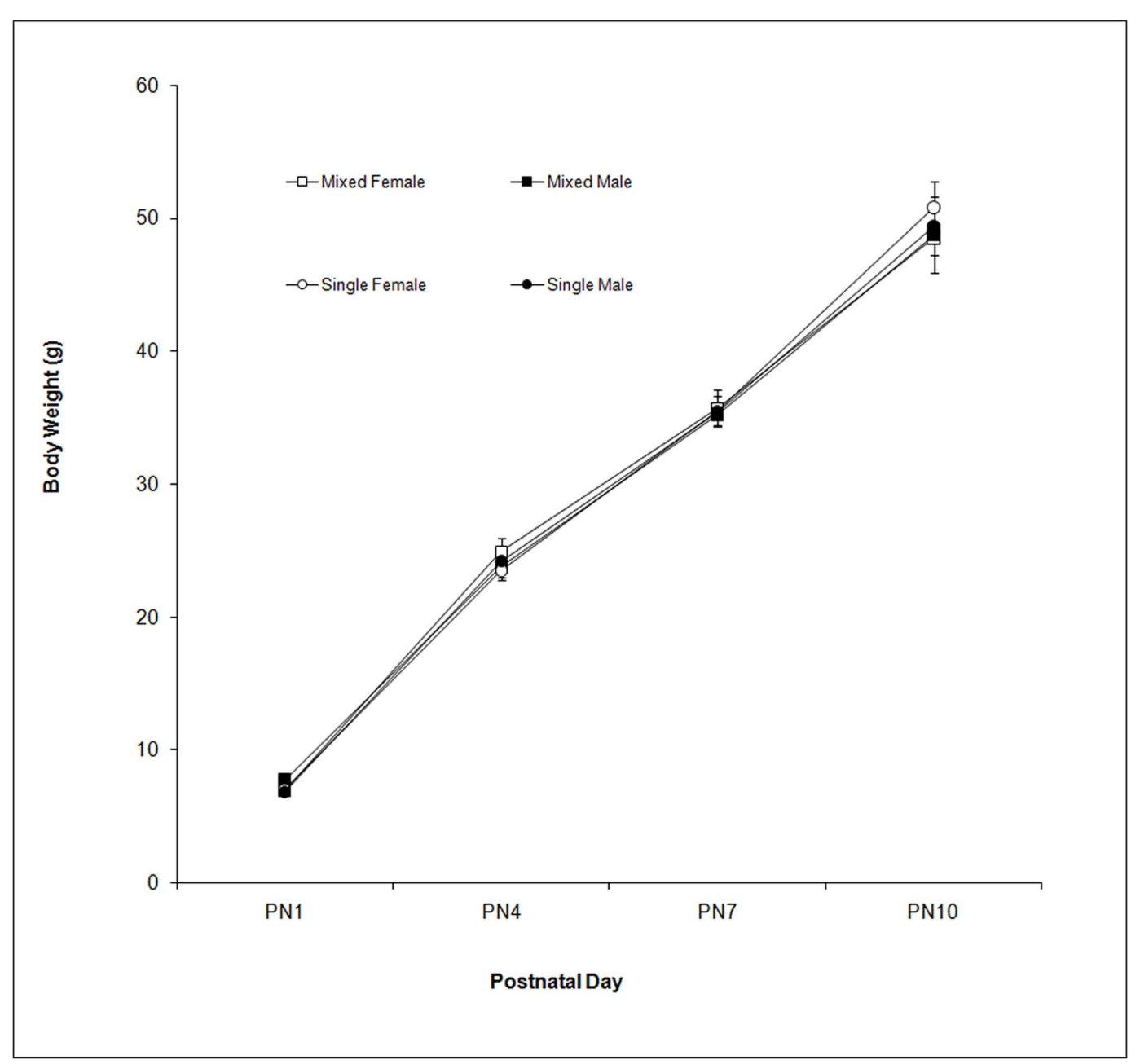

FIGURE 1 | Mean ( \pm SEM) body weight ( $g$ ) is presented for mixed- (squares) and single- (circles) sex litters for female (open symbols) and male (closed symbols) rats over postnatal days. All groups gained weight over this period with no effect of LGC or Sex seen.

\section{FREQUENCIES OF BEHAVIORS}

The effects of LGC and sex on these behaviors on PN4, 7, and 10 are shown in Tables 2-4, respectively. None of these behaviors supported significant main effects of LGC or Sex or their interaction $\left(P^{\prime}>0.10\right)$. However, some behaviors show Day or Sex $\times$ Day effects. There is a significant interaction of Sex $\times$ Day for Carry, $F(2,76)=3.83 ; P<0.05$. As seen in Tables 2-4, this interaction likely reflects that the dam increased carrying male pups over days and decreased carrying female pups over days. Burrowing also shows a significant $\operatorname{Sex} \times$ Day interaction, $F(2,76)=3.50 ; P<0.05$. Dams with female pups show decreases in burrowing over days whereas dams with male pups burrow about the same amount over days. There is a trend for a significant effect of Day for Climbing, $F(2,76)=2.41 ; P<0.10$. The data in Tables $2-4$ suggest that this reflects a tendency to increase on PN7 over what is seen on PN4 and then decrease on PN10. The dam's behavior of grooming herself shows a trend toward significance for the Sex $\times$ Day interaction, $F(2,76)=2.38 ; P<0.10$ and this likely reflects that her grooming tends to decrease over days with male pups but tends to increase over days with female pups. There are no significant effects of Day or its interactions with LGC or Sex for blanket nursing or for rearing $\left(P_{S}^{\text {s }}>0.10\right)$.
Table 2 | Mean ( \pm SEM) total frequencies of each behavior across 10-min sessions conducted on PN4.

\begin{tabular}{llllll}
\hline Variable & \multicolumn{2}{c}{ Mixed-sex litters } & & \multicolumn{2}{c}{ Same-sex litters } \\
\cline { 2 - 3 } \cline { 6 - 6 } & Male & Female & & Male & Female \\
\hline Carry & $1.9(1.1)$ & $1.3(0.4)$ & & $2.0(0.6)$ & $1.6(0.4)$ \\
Blanket & $2.8(1.3)$ & $2.9(1.1)$ & & $1.2(0.6)$ & $0.1(0.01)$ \\
Burrowing & $3.9(1.4)$ & $6.7(1.2)$ & & $5.7(1.3)$ & $6.9(1.3)$ \\
Climbing & $7.9(1.3)$ & $7.8(1.0)$ & & $8.8(1.2)$ & $9.2(1.1)$ \\
Rearing & $5.8(1.0)$ & $4.2(1.0)$ & & $5.0(1.0)$ & $5.0(1.4)$ \\
Grooming & $6.8(1.2)$ & $3.0(0.7)$ & & $5.4(1.1)$ & $4.5(0.9)$
\end{tabular}

\section{LATENCY TO PUP CONTACT}

The latencies to contact the pup over days are shown in Figure 2. There is a trend for dams to contact male pups more quickly than female pups as supported by the trend toward significance for the Sex effect, $F(1,76)=3.21 ; P<0.10$. Although the main effects of LGC and Day are not significant $\left(P^{s}>0.10\right)$, there is a significant 
Table 3 | Mean ( \pm SEM) total frequencies of each behavior across 10-min sessions conducted on PN7.

\begin{tabular}{lrrlll}
\hline \multirow{2}{*}{ Variable } & \multicolumn{2}{c}{ Mixed-sex litters } & & \multicolumn{2}{c}{ Same-sex litters } \\
\cline { 2 - 3 } \cline { 6 - 6 } & Male & Female & & Male & Female \\
\hline Carry & $2.3(0.9)$ & $2.4(0.9)$ & & $2.0(0.7)$ & $1.9(0.5)$ \\
Blanket & $1.8(1.1)$ & $1.4(0.6)$ & & $1.0(0.6)$ & $2.0(1.2)$ \\
Burrowing & $4.6(1.1)$ & $5.6(0.9)$ & & $7.6(1.6)$ & $4.5(1.0)$ \\
Climbing & $10.2(1.7)$ & $6.7(1.2)$ & & $9.3(2.8)$ & $9.0(4.7)$ \\
Rearing & $4.9(1.2)$ & $4.0(0.9)$ & & $4.3(1.1)$ & $5.1(1.3)$ \\
Grooming & $4.0(0.8)$ & $3.7(0.8)$ & & $5.9(1.0)$ & $6.8(1.3)$ \\
\hline
\end{tabular}

Table 4 | Mean ( \pm SEM) total frequencies of each behavior across 10-min sessions conducted on PN10.

\begin{tabular}{lcclll}
\hline Variable & \multicolumn{2}{c}{ Mixed-sex litters } & & \multicolumn{2}{c}{ Same-sex litters } \\
\cline { 2 - 3 } & Male & Female & & Male & Female \\
\hline Carry & $3.0(0.8)$ & $1.0(0.5)$ & & $2.4(0.5)$ & $0.6(0.4)$ \\
Blanket & $2.0(1.0)$ & $3.0(1.3)$ & & $1.5(1.0)$ & $2.2(1.1)$ \\
Burrowing & $4.2(1.5)$ & $6.1(1.5)$ & & $2.3(1.2)$ & $6.3(1.2)$ \\
Climbing & $7.0(1.6)$ & $7.3(1.5)$ & & $5.9(1.7)$ & $8.0(1.4)$ \\
Rearing & $4.0(1.5)$ & $3.9(3.2)$ & & $4.6(1.7)$ & $3.5(0.9)$ \\
Grooming & $4.3(1.0)$ & $3.9(0.8)$ & & $3.8(1.0)$ & $4.3(0.7)$
\end{tabular}

LGC $\times$ Sex $\times$ Day effect, $F(2,76)=8.14 ; P<0.001$. Post hoc univariate statistics revealed significant LGC $\times$ Sex effects on PN4 and PN10 $(P$ 's $<0.01)$. As seen in Figure $2 \mathrm{~A}$, dams with mixed-sex male pups take less time to contact their pup compared to dams with mixedsex female pups. and this LGC effect is not seen on PN7 or PN10. In contrast, as seen in Figure 2B, dams with single-sex male pups take longer to contact their pup on PN4 compared to dams with singlesex female pups. However, latencies decrease on PN10 for dams with single-sex male pups and increase for dams of mixed-sex female pups.

\section{ANOGENITAL AND BODY LICKING}

The total times spent licking the pup in the anogenital region and in other body regions are shown in Figures 3 and 4 respectively. Anogenital licking times differ by $\operatorname{Sex}, F(1,38)=4.76 ; P<0.05$, but not by LGC and do not change over Days ( $P^{\prime}$ s $\left.>0.10\right)$. Dams lick their male pups more than female pups as shown in Figure 3A for mixed-sex litters and in Figure 3B for single-sex litters. Dams also lick other body parts of their male pups more than of their female pups as seen in Figure 4. This is supported by the significant effect of Sex, $F(1,38)=4.85 ; P<0.05$ and can be seen for mixed-sex litters in Figure 4A and for single-sex litters in Figure 4B. There are no significant effects of LGC or Day or their interactions for body licking $\left(P^{\prime} \mathrm{s}>0.10\right)$.

\section{DNA METHYLATION OF THE OPRM1 GENE}

DNA methylation of the Oprm1 gene promoter region in hippocampus is greater in single-sex litters compared to mixed-sex litters as supported by the significant LGC effect, $F(1,57)=8.81$;
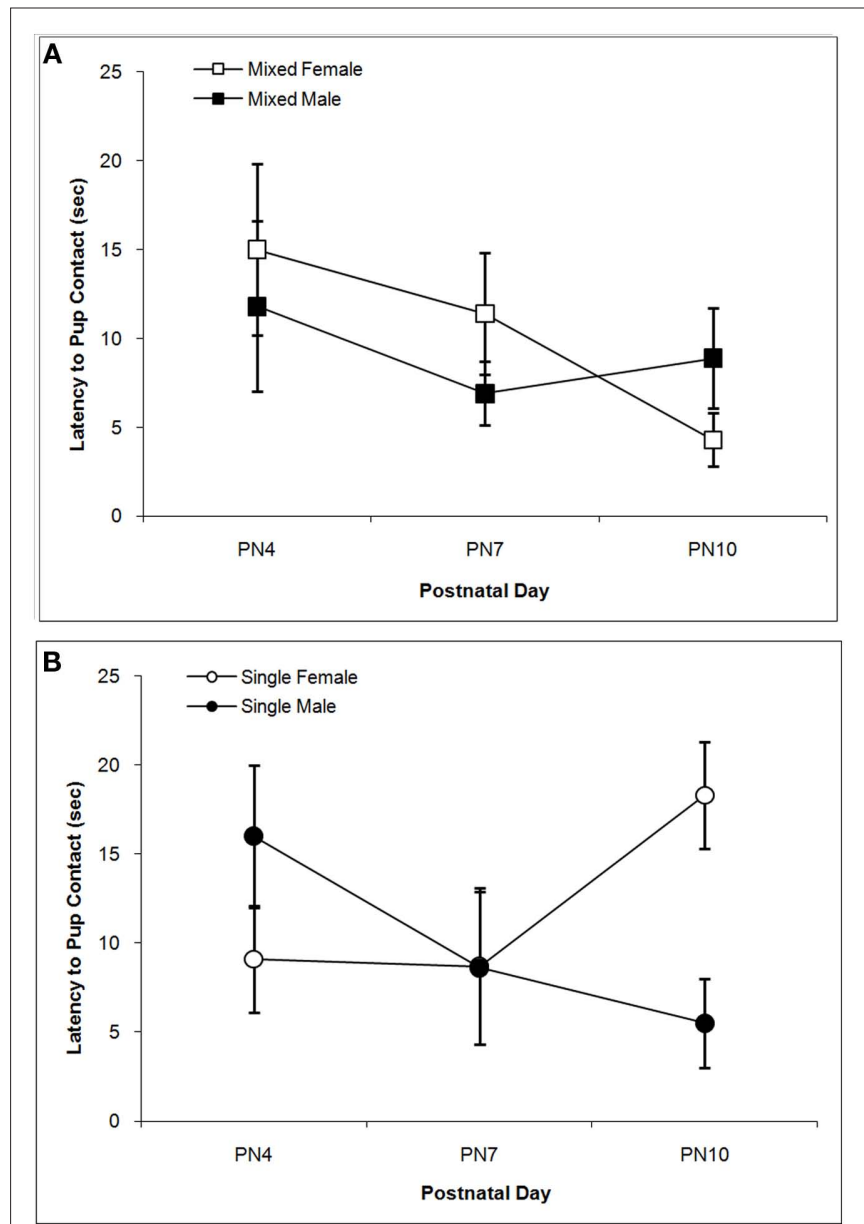

FIGURE 2 | Mean ( \pm SEM) latencies (s) for the dam to contact the pup are presented for mixed- [squares; (A)] and single- [circles; $(B)$ ] sex litters for male (closed symbols) and female (open symbols) rats over postnatal days. Dams with single-sex litters took longer to contact their male pups on PN4 and their female pups on PN10 relative to other days and to dams of mixed-sex litters. Dams tended to take longer to contact female vs. male pups. See text for statistics.

$P<0.005$, but did not differ by Sex $(P>0.10)$. Methylation levels also differ significantly by CpG site, $F(6,342)=4.90 ; P<0.001$. Post hoc univariate comparisons reveals significant LGC effects at CpG sites $-59,-20$, and 33 ( $P$ 's $<0.05)$. Compared to mixed-sex litters seen in Figure 5A, hypermethylation at most CpG sites can be seen in Figure 5B for single-sex litters. For ease of presentation, Figure 5C shows the means across CpG sites by LGC and Sex in Hippocampus.

In NAc, single-sex males have the highest mean DNA methylation level over the Oprm1 gene promoter region and this is supported by the significant LGC $\times$ Sex interaction, $F(1,57)=4.33$; $P<0.05$. Neither the LGC nor Sex main effect is significant $(P$ 's $>0.10)$ but methylation levels differ significantly by CpG site, $F(6,342)=4.33 ; P<0.001$. Post hoc univariate comparisons reveal a significant LGC $\times$ Sex effect at CpG site $-107(P<0.05)$. This is shown in Figure 6A for mixed-sex litters and in Figure 6B for single-sex litters. The means across $\mathrm{CpG}$ sites for all four groups are shown in Figure 6C. 

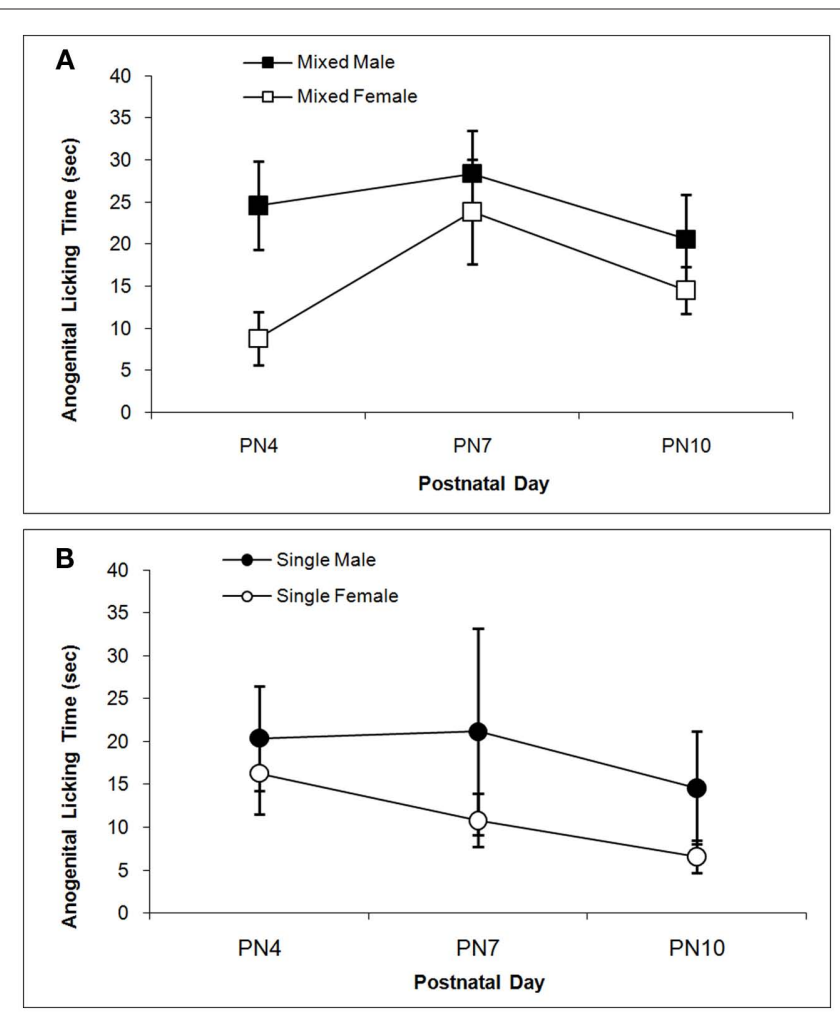

FIGURE 3 | Mean ( \pm SEM) times the dam spent licking the anogenital region of her pup are presented for mixed- [squares; (A)] and single[circles; (B)] sex litters for male (closed symbols) and female (open symbols) rats over postnatal days. Dams lick the anogenital region of male pups more than female pups. See text for statistics.

Single-sex males tend to have the highest mean DNA methylation level over the Oprm1 gene promoter region in CP. This statement is supported by the trends toward significance of the main effect of Sex, $F(1,57)=3.77 ; P<0.10$ and the interaction of LGC $\times$ Sex, $F(1,57)=3.07 ; P<0.10$. The $\mathrm{CpG}$ effect was not significant, $P>0.10$, in this brain region. These data are shown in Figures $7 \mathrm{~A}-\mathrm{C}$. We find no significant effects on DNA methylation in cerebellum for LGC or Sex or CpG site or any significant interactions $\left(P_{s}^{\prime}>0.10\right.$; data not shown).

\section{DISCUSSION}

These experiments provide important new data on epigenetic alterations linked to the subtle early life manipulation of modifying LGC as well as to sex differences both of which affected maternal behavior. Results from the present study confirm and extend prior work showing sex differences and modest LGC effects on mother-pup behaviors as well as support for the involvement of the mu-opioid system in these behaviors. We demonstrate that dams provide more maternal care to their male pups than to their female pups and that LGC interacts with sex of pup and postnatal day to alter latency to pup contact. Further, both sex of pup and LGC had significant effects on DNA methylation levels of the Oprm1 gene promoter region. Male rats raised in single-sex litters show Oprm1 hypermethylation, particularly in NAc and $\mathrm{CP}$, and rats of both sexes raised in single-sex litters show hypermethylation

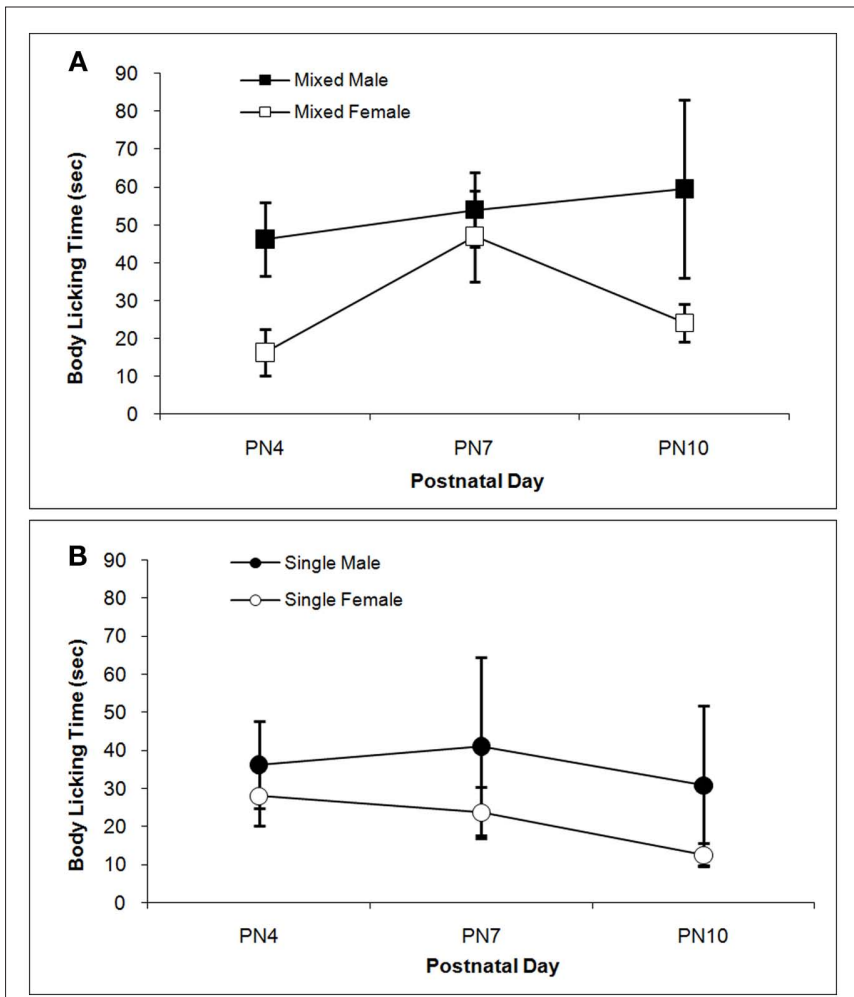

FIGURE 4 | Mean (ISEM) times the dam spent licking the body of her pup except in the anogenital region are presented for mixed- [squares; (A)] and single- [circles; (B)] sex litters for male (closed symbols) and female (open symbols) rats over postnatal days. Dams lick the body of male pups more than female pups. See text for statistics.

in hippocampus compared to rats raised in mixed-sex litters. It is unlikely that these effects can be explained by gross developmental differences because we found that neither sex nor LGC altered body weight gain. These data are the first to demonstrate that sex and composition of the family unit is associated with epigenetic alterations in the DNA methylation of Oprm1 gene promoter region. These levels of methylation may reflect differences in the levels of maternal care received.

The present study confirms and extends prior work because we demonstrated sex dependency of some mother-pup behaviors. As others reported (Moore and Morelli, 1979; Richmond and Sachs, 1984; Moore and Chadwick-Dias, 1986), we showed that dams licked their male pups more in the anogenital region compared to their female pups. We also found that dams with male pups licked other regions of the body more than dams with female pups. Sex differences were seen in the behavior of carrying or handling the pup. Moore and Morelli (1979) reported that introducing a new male pup to the litter increased the dam's handling pups with her forepaws. We saw that dams with male pups showed increasing times carrying them over postnatal days compared to dams with female pups that showed decreasing carrying times over days. Latency to contact a pup tended to be shorter for male pups than for female pups in our study although Moore and Morelli (1979) found no sex differences in this measure. 

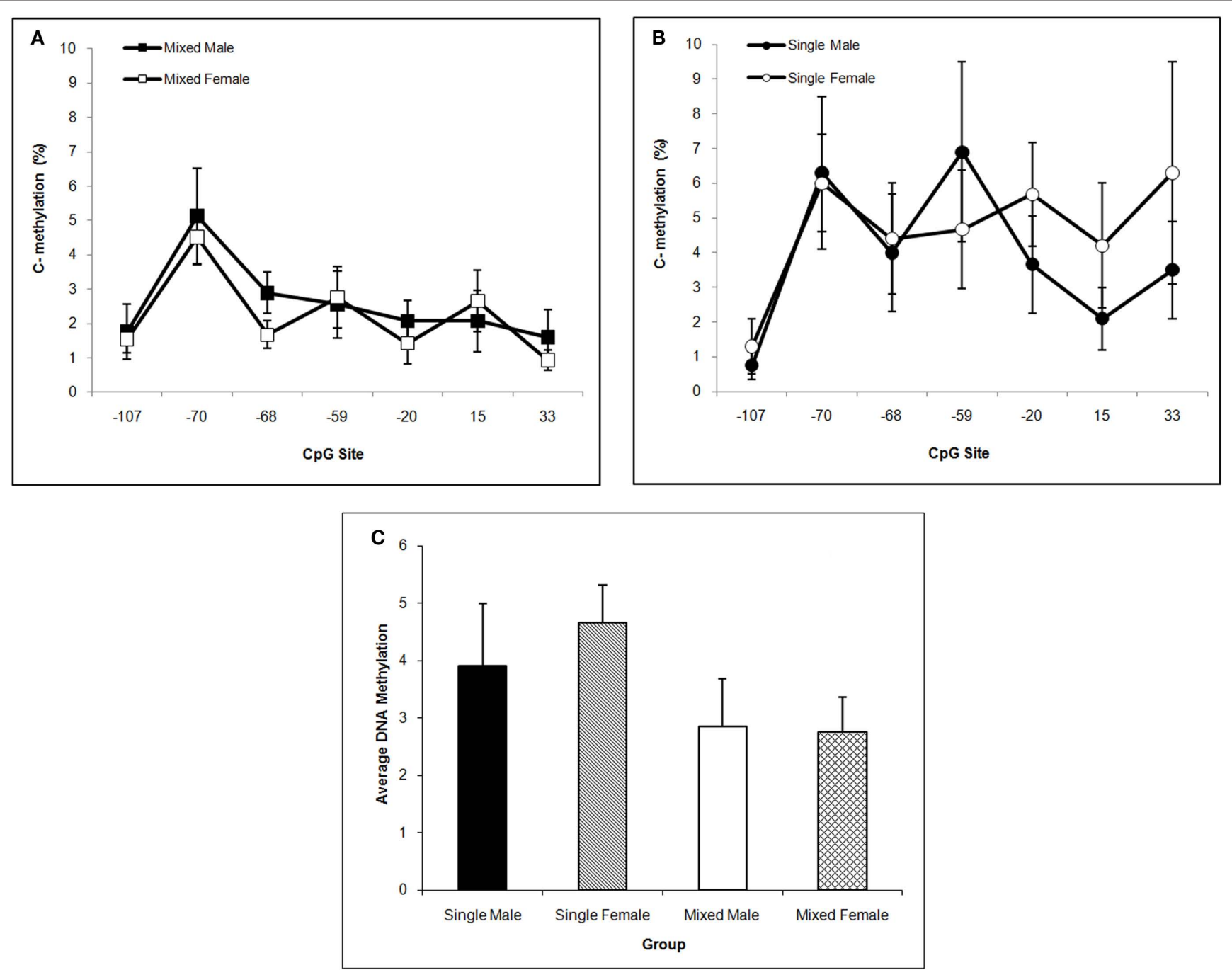

FIGURE 5 | Mean (ISEM) DNA methylation levels of the Oprm 1 gene promoter region in hippocampus are presented for mixed- [squares; (A)] and single[circles; (B)] sex litters for male (closed symbols) and female (open symbols) rats over CpG site. Mean DNA methylation levels across CpG sites are shown in (C). Levels are higher in single- vs. mixed-sex litters and differ by CpG site. Post hoc analyses reveal significant effects at $-59,-20$, and 33 sites. See text for statistics.
Similar to previous work (Moore and Morelli, 1979; Alleva et al., 1989; Cirulli et al., 1997), we found that LGC had modest effects on mother-pup behaviors. Dams of male mice raised in single-sex litters spent more time engaged in nest-building and in archedback or active nursing compared to dams of single-sex females or mixed-sex litters (Alleva et al., 1989; Cirulli et al., 1997). We did not see active nursing in our 10-min sessions although we rated blanket nursing and found no significant LGC or Sex effects. In fact, only one measure showed an LGC effect in the present study and it interacted with Sex and Day. Dams of male pups in mixed-sex litters showed the lowest latencies to pup contact and it remained low across the 3 postnatal days assessed. However, if the dams' male pups were in single-sex litters, then the latency to contact was high on PN4 and not unlike the levels seen for dams of female pups. On subsequent days, single-sex male pups were then contacted in a short time frame not unlike the times seen for mixed-sex male pups. In contrast, the dams' latencies to retrieve female pups from single-sex litters increased on PN10 whereas latencies decreased on this day for dams of mixed-sex females. The day effect seen for male pups is similar to findings from Moore and Morelli (1979). In their procedure, the litter remained with the dam and a new pup (male or female) was introduced. If a male pup was introduced to dam with all male pups, the latency to retrieve was very high on PN3 and decreased to very low levels on PN10. We can speculate that the dam's ability to discriminate the sex of her pups may be facilitated by the presence of pups of both sexes so that if she has only males in her litter, it may take a few days for her to retrieve or contact male pups as efficiently as dams with mixed-sex litters.

There are some methodological differences in procedures used to assess sex or LGC effects on maternal behavior between our study and those of others. Observations of mother-pup interactions were made in the home cage in the previous studies whereas in the present study, observations were made in a separate test room with dam and one pup placed in a test cage after a short 

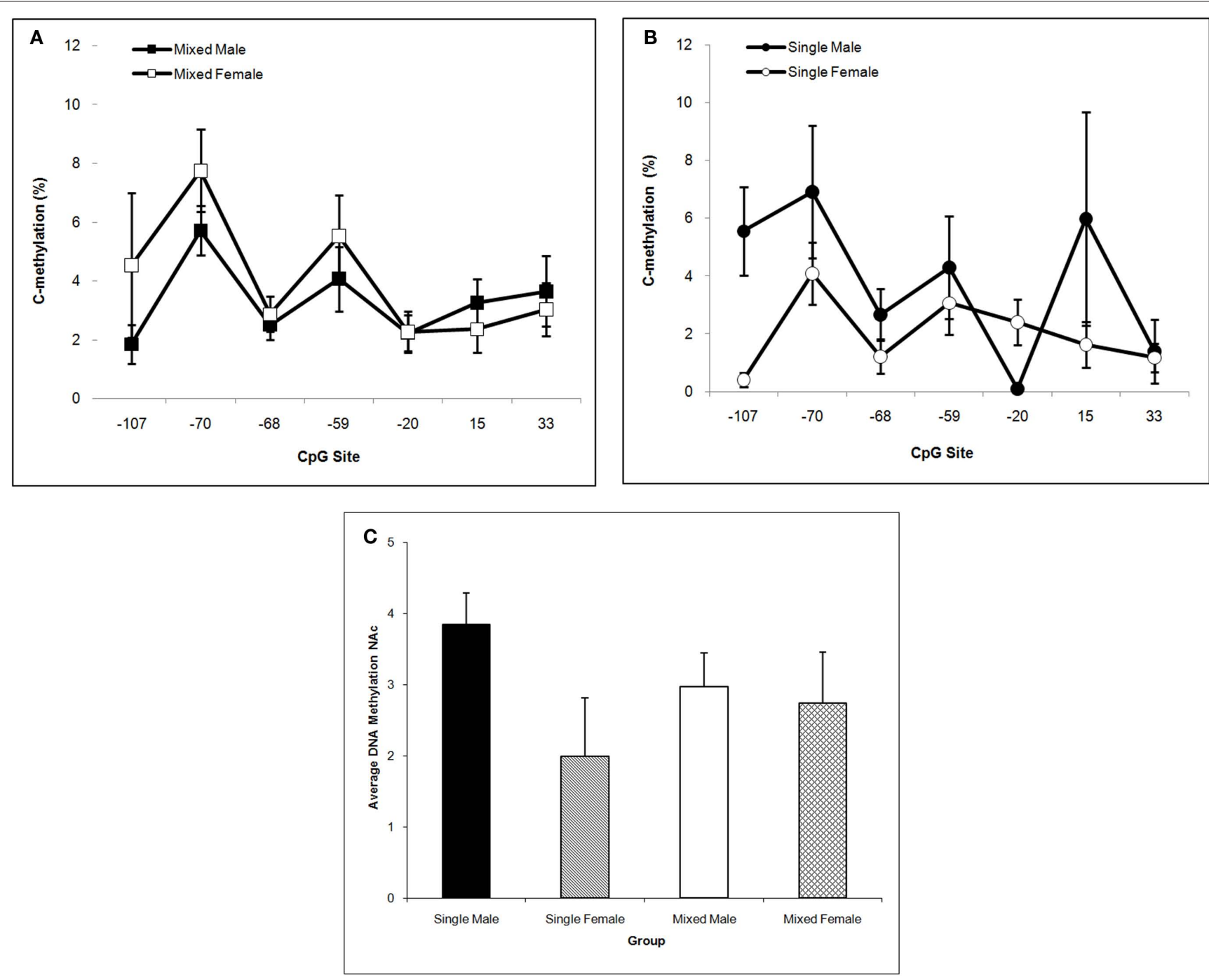

FIGURE 6 | Mean ( \pm SEM) DNA methylation levels of the Oprm1 gene promoter region in nucleus accumbens are presented for mixed- [squares; $(A)$ ] and single- [circles; (B)] sex litters for male (closed symbols) and female (open symbols) rats over CpG site. Mean DNA methylation levels across CpG sites are shown in (C). Levels are highest in males of single-sex litters and differ by $\mathrm{CpG}$ site. Post hoc analyses reveal a significant LGC $\times$ Sex effect at 107. See text for statistics. separation period. The former procedure allowed assessing behavior under natural and undisturbed conditions whereas the latter procedure was likely disruptive to the dam and pup. However, such a disruption can stimulate a bout of maternal behavior that may enhance the ability to find significant effects of the experimental manipulations. Also, the dam, and possibly the pup, may habituate to these effects over subsequent test days (Kosten and Kehoe, 2010). The reason we chose to use this procedure is that, unlike previous studies, it allowed us to study sex and LGC independently. That is, we employed twice as many mixed-sex litters and used half to sample a pup of each sex. The previous studies had only one mixed-sex group to compare to single-sex female and single-sex male litters and thus could not assess the effect of sex alone or its interaction with LGC.

Both LGC and sex affected DNA methylation levels of the Oprm1 gene promoter region in the present study. We found hypermethylation in single-sex litters in hippocampus with no changes seen in cerebellum. In NAc single-sex male litters showed hypermethylation, an effect that trended toward significance in the CP. The Oprm1 gene codes for the mu-opioid receptor that is widespread in the central nervous system. It is the site of action of beta-endorphins as well as for several opioid drugs such as morphine and heroin. This system is involved in many physiological and behavioral functions most notably in analgesia, drug addiction, and motivation to seek natural rewards (Kreek et al., 2005; Koob and Le Moal, 2008). The contribution of the mu-opioid system to attachment behavior is particularly relevant to the present study. Early pharmacological studies suggested that endogenous opioids are released in the infant during caretaking and that this serves to motivate it to seek out and maintain closeness to its caregiver (Kehoe and Blass, 1986; Kalin et al., 1988; Carden et al., 1991; Nelson and Panksepp, 1998).

More recent molecular genetic studies support the contribution of the mu-opioid system in infant-mother attachment. Mice lacking the Oprm1 gene emit fewer USVs after separation from 

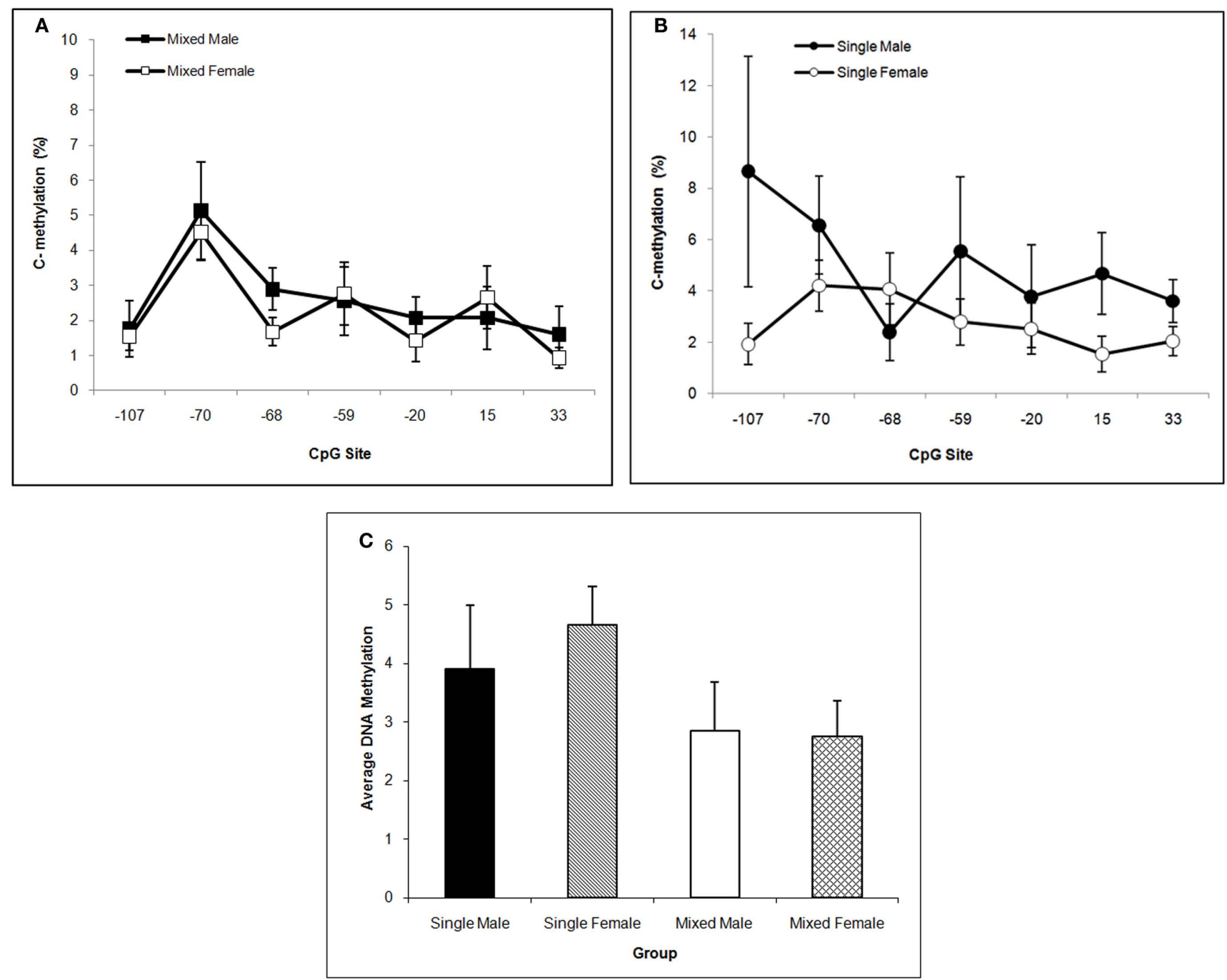

FIGURE 7 | Mean ( \pm SEM) DNA methylation levels of the Oprm 1 gene promoter region in caudate-putamen are presented for mixed- [squares; (A)] and single- [circles; (B)] sex litters for male (closed symbols) and female (open symbols) rats over transcription site. Mean DNA methylation levels across CpG sites are shown in (C). Levels tend to be highest in males, particularly those from single-sex litters. See text for statistics. their dam, a behavior that is not modulated by morphine in the knock-out as it is in the wild-type mouse (Moles et al., 2004). Further, a polymorphism of the OPRM1 gene in infant primates $(\mathrm{C} 77 \mathrm{G})$ associates with vocalizations and expression of attachment behaviors (e.g., clinging behavior; Barr et al., 2008). That is, infants with a $\mathrm{G}$ allele show persistence in vocalization emissions and increasing social contact after repeated separations from the mother whereas infant primates with the C/C genotype do not (Barr et al., 2008). In humans, the G allele of the OPRM1 A118G variant has been shown to relate to lower potency of analgesic effects of opioids and greater pain experiences as well as greater distress after social rejection (Chou et al., 2006; Way et al., 2009). The $\mathrm{G}$ allele of the OPRM1 gene is associated with reduced levels of mu-opioid receptor mRNA and protein compared to the A allele (Kroslak et al., 2007). Among children living in disruptive family environments, the $118 \mathrm{G}$ allele is associated with greater quality of parental relationship and fewer parental arguments (Copeland et al., 2011). Perhaps this reflects that these children expressed greater attachment behaviors as infants as suggested by the nonhuman primate study.

In general, DNA methylation means that transcriptional factors are not accessed and less gene promoter is expressed (Razin, 1998). In the case of the Oprm1 gene, DNA hypomethylation associates with increased OPRM1 transcription (Andria and Simon, 1999; Hwang et al., 2009). In fact, another early life manipulation, exposure to a high-fat diet, also increased methylation of the Oprml gene and this is associated with decreased mRNA expression of the mu-opioid receptor in reward regions of the brains of mice (Vucetic et al., 2011). The increase in Oprm1 DNA methylation seen in male rats in the present study, particularly those raised in single-sex litters, suggests that they too have lower mu-opioid receptor availability. Such rats would be predicted to 
have lower analgesic effects of morphine. Indeed, morphine is less effective in male mice raised in same-sex litters compared to male mice raised in mixed-sex litters (Alleva et al., 1986). Further, our findings that LGC altered DNA methylation of the Oprm1 gene promoter region in brain regions that contribute to drug reward (NAc, hippocampus, CP) but not in a region not involved with this effect (cerebellum), suggest that this early life manipulation may also affect vulnerability to addiction. The lack of significant effects of LGC or sex on global DNA methylation levels in these regions of interest (data not shown) supports our finding that changes in the Oprm1 DNA methylation levels are specific. These brain regions are also involved in stress responsivity (Chrousos and Gold, 1992), memory (Scoville and Milner, 1957; McGaugh, 2000), and emotion (Gray, 1982; McHugh et al., 2004; Barkus et al., 2010). Phenotypes related to these constructs may also be modified by LGC or sex via a DNA methylation-induced alteration in the Oprm1 gene.

DNA methylation of CpGs in transcription factor binding sites reduces the binding affinity of cognate transcription factors and their ability to transactivate gene expression. In hippocampus, we find that LGC affected the $+33 \mathrm{CpG}$ site specifically increasing methylation in rats from single-sex litters (see Figure 5). This CpG site is located in an E2F binding site (TESS R08845; Schug and Overton, 1977). E2Fs are a family of transcription factors that have been shown to regulate the cell cycle and DNA biosynthesis and play a central role in the development of the central nervous system (Swiss and Casaccia, 2010). No mammalian transcription factor binding sites have been identified that contain the -59 and -20 CpG sites (TESS; Schug and Overton, 1977). The -107 CpG site is significantly altered in NAc by LGC in a sex-dependent manner. That is, male pups raised in single-sex litters show greater methylation at this site compared to male pups raised in mixed-sex litters. In contrast, females raised in single-sex litters show lower

\section{REFERENCES}

Alleva, E., Caprioli, A., and Laviola, G. (1986). Postnatal social environment affects morphine analgesia in male mice. Physiol. Behav. 36, 779-781.

Alleva, E., Caprioli, A., and Laviola, G. (1989). Litter gender composition affects maternal behavior of the primiparous mouse dam (Mus musculus). J. Comp. Psychol. 103, 83-87.

Andria, M. L., and Simon, E. J. (1999). Localization of promoter elements in the human mu-opioid receptor gene and regulation by DNA methylation. Brain Res. Mol. Brain Res. 70, 54-65.

Barkus, C., McHugh, S. B., Sprengel, R., Seeburg, P. H., Rawlins, J. N. P., and Bannerman, D. M. (2010). Hippocampal NMDA receptors and anxiety: at the interface between cognition and emotion. Eur. J. Pharmacol. 626, 49-56.

Barr, C. S., Schwandt, M. L., Lindell, S. G., Higley, J. D., Mestripieri, D., Goldman, D., Suomi, S. J., and Heilig, M. (2008). Variation at the mu-opioid receptor gene (OPRM1) influences attachment behavior in infant primates. Proc. Natl. Acad. Sci. U.S.A. 105, 5277-5281.

Beatty, W. W., and Beatty, P. A. (1970). Hormonal determinants of sex differences in avoidance behavior and reactivity to electric shock in the rat. J. Comp. Physiol. Psychol. 73, 446-455.

Carden, S. E., Barr, G. A., and Hofer, M.A. (1991). Differential effects of specific opioid receptor agonists on rat pup isolation calls. Brain Res. Dev. Brain Res. 62, 17-22.

Carlezon, W.A., Duman, R.S., and Nestler, E. J. (2005). The many faces of CREB. Trends Neurosci. 28, 436-445.

Carroll, M. E., Morgan, A. D., Campbell, U. C., Lynch, W. J., and Dess, N. K. (2002). Cocaine and heroin i.v. selfadministration in rats selectively bred for differential saccharin intake: phenotype and sex differences. Psychopharmacology 161, 304-313.

Caspi, A., Sugden, K., Moffitt, T. E., Taylor, A., Craig, I. W., Harrington, H., Mccaly, J., Mill, J., Martin, J., Braithwaite, A., and Pouton, R. (2003). Influence of life stress on depression: moderation by

methylation at this site compared to their mixed-sex litter counterparts (see Figure 6). The $-107 \mathrm{CpG}$ site is located in overlapping CREB (TESS R02710) and activator protein-1 (AP-1; TESS R00368) transcription factor binding sites. CREB, in addition to its role in intracellular signaling of the cAMP/PKA pathway, is essential for survival and expansion of neural progenitor cells, while both CREB and activator protein-1 (AP-1), a dimer of c-fos and Jun family members, appears to control synaptic plasticity (Flavell and Greenberg, 2008; Dworkin et al., 2009). CREB levels in NAc are related to the rewarding and aversive effects of drugs of abuse, including opiates, as well as to chronic effects of drug exposure, such as tolerance, dependence, and withdrawal (Carlezon et al., 2005). Further, both depression and anxiety are linked to CREB activity in NAc (Carlezon et al., 2005). Interestingly, there are gender differences in the rates of all of these disorders (see Introduction) raising the possibility that sexual dimorphism in DNA methylation of the CREB CPG site of the OPRM1 gene in humans may exist and may contribute to the differential risk or resiliency to develop these disorders.

The present study adds to the literature demonstrating that epigenetic modification of gene expression and resulting changes in phenotypic expression may be mediated via maternal care (Weaver et al., 2004; Roth et al., 2009). Further, these effects may be transmitted to future generations (Meaney, 2001; Roth et al., 2009) through non-genomic transmission of maternal behavior (Francis et al., 1999; Champagne and Meaney, 2001) or perhaps via imprinting the effects from parent to daughter cells.

\section{ACKNOWLEDGMENTS}

This research was supported by grant DA 020117 (Therese A. Kosten). We greatly acknowledge the technical assistance provided by A. Aruffo, M. Kosten, P. O’Malley, M. Rengasamy, J. Taylor, X. Xiang, and A. Yarnall.

a polymorphism in the 5 -HTT gene. Science 301, 386-389.

Champagne, F., and Meaney, M. J. (2001). Like mother, like daughter: evidence for non-genomic transmission of parental behavior and stress responsivity. Prog. Brain Res. 133 287-302.

Champagne, F. A., Francis, D. D., Mar, A. and Meaney, M. J. (2003). Variations in maternal care in the rat as a mediating influence for the effects of environment on development. Physiol. Behav. 79, 359-371.

Chou, W.-Y., Wang, C.-H., Liu, P.-H., Liu, C.-C., Tseng, C.-C., and Jawan, B. (2006). Human opioid receptor A118G polymorphism affects intravenous patient-controlled analgesia morphine consumption after total abdominal hysterectomy. Anesthesiology 105, 334-337.

Chrousos, G. P., and Gold, P. W. (1992). The concepts of stress and stress system disorders. Overview of physical and behavioral homeostasis. J. Am. Med. Assoc. 267, 1244-1252.
Cicero, T. J., Aylward, S. C., and Meyer, E. R. (2003). Gender differences in the intravenous self-administration of mu opiate agonists. Pharmacol. Biochem. Behav. 74, 541-549.

Cicero, T. J., Ennis, T., Ogden, J., and Meyer, E. R. (2000). Gender differences in the reinforcing properties of morphine. Pharmacol. Biochem. Behav. 65, 91-96.

Cicero, T. J., Nock, B., O'connor, L., and Meyer, E. R. (2002). Role of steroids in sex differences in morphine-induced analgesia: activational and organization effects. J. Pharmacol. Exp. Ther. 300, 695-701.

Cirulli, F., Adriani, W., and Laviola, G. (1997). Sexual segregation in infant mice: behavioural and neuroendocrine responses to D-amphetamine administration. Psychopharmacology (Berl.) 134, 140-152.

Copeland, W. E., Sun, H., Costello, E. J., Angold, A., Heilig, M. A., and Barr, C. S. (2011). Child m-opioid receptor gene variant influences parent-child 
relations. Neuropsychopharmacology $36,1165-1172$.

Craft, R. M. (2003). Sex differences in opioid analgesia: "from mouse to man". Clin. J. Pain 19, 175-186.

Dumas, T.C. (2005). Late postnatal maturation of excitatory synaptic transmission permits adult-like expression of hippocampal behaviors. Hippocampus $15,562-578$.

Dunn, A. J., and Berridge, C. W. (1990). Physiological and behavioral responses to corticotropin-releasing factor administration: is CRF a mediator of anxiety or stress responses? Brain Res. Rev. 15, 71-100.

Dworkin, S. J., Malaterre, J., Hollande, F., Darcy, P. K., Ramsay, R. G., and Mantamadiotis, T. (2009). cAMP response element binding protein is required for mouse neural progenitor cell survival and expansion. Stem Cells 27, 1347-1357.

Flavell,S.W., and Greenberg, M.E. (2008). Signaling mechanisms linking neuronal activity to gene expression and plasticity of the nervous system. Annu. Rev. Neurosci. 31, 563-590.

Fombonne, E. (2003). Epidemiological surveys of autism and other pervasive developmental disorders: an update. J. Autism Dev. Disord. 33, 365-382.

Francis, D. D., Diorio, J., Liu, D., and Meaney, M. J. (1999). Nongenomic transmission across generations of maternal behavior and stress responses in the rat. Science 286, 1155-1158.

Grant, B. F., Goldstein, R. B., Chou, S. P., Huang, B., Stinson, F. S., Dawson, D. A., Saha, T. D., Smith, S. M., Pulay, A. J., Pickering, R. P., Ruan, W. J., and Compton, W. M. (2009). Sociodemographic and psychopathologic predictors of first incidence of DSM-IV substance use, mood and anxiety disorders: results from the Wave 2 National Epidemiologic Survey on Alcohol and Related Conditions. Mol. Psychiatry 14, 1051-1066.

Gray, J. A. (1982). The Neuropsychology of Anxiety: An Enquiry into the Functions of the Septo-Hippocampal System. Oxford: Oxford University Press.

Greenfield, S. F., Back, S. E., Lawson, K., and Brady, K. T. (2010). Substance abuse in women. Psychiatr. Clin. North Am. 33, 339-355.

Gubernick, D. J., and Alberts, J. R. (1983). Maternal licking of young: resource exchange and proximate controls. Physiol. Behav. 31, 593-601.

Hammer, R.P. (1990).m-Opiate receptor binding in the medial preoptic area is cyclical and sexually dimorphic. Brain Res. 515, 187-192.

Hwang, C. K., Song, K.Y., Kim, C. S., Choi, H. S., Guo, X. H., Law, P. Y., Wei, L. N., and Loh, H. H. (2009). Epigenetic programming of mu-opioid receptor gene in mouse brain is regulated by $\mathrm{MeCP} 2$ and Brg1 chromatin remodelling factor. J. Cell. Mol. Med. 13, 3591-3615.

Jones, P. A., and Taylor, S. M. (1980). Cellular differentiation, cytidine analogs and DNA methylation. Cell 20, 85-93.

Kalin, N. H., Shelton, S. E., and Barksdale, C. M. (1988). Opiate modulation of separation-induced distress in nonhuman primates. Brain Res. 440, 285-292.

Kehoe, P., and Blass, E. M. (1986). Opioidmediation of separation distress in 10-day-old rats: reversal of stress with maternal stimuli. Dev. Psychobiol. 19, 385-398.

Kitay, J. I. (1961). Sex differences in adrenal cortical secretion in the rat. Endocrinology 68, 818-824.

Koob, G. F., and Le Moal, M. (2008). Addiction and the brain antireward system. Annu. Rev. Psychol. 59, 29-53.

Kosten, T. A., and Kehoe, P. (2010). The immediate and enduring effects of neonatal isolation on maternal behavior in rats. Int. J. Dev. Neurosci. 28, 53-61.

Kosten, T. A., Lee, H. J., and Kim, J. J. (2006). Early life stress impairs fear conditioning in adult male and female rats. Brain Res. 1087, 142-150.

Kreek, M. J., Nielsen, D. A., Butelman, E. R., and Laforge, K. S. (2005). Genetic influences on impulsivity, risk taking, stress responsivity, and vulnerability to drug abuse and addiction. Nat. Neurosci. 8, 1450-1457.

Kroslak, T., Laforge, K. S., Ho, A., Nielsen, D. A., and Kreek, M. J. (2007). The single nucleotide polymorphism A118G alters functional properties of the human mu opioid receptor. $J$. Neurochem. 103, 77-87.

Kudielka, B. M., and Kirschbaum, C. (2005). Sex differences in HPA axis responses to stress: a review. Biol. Psychiatry 69, 113-132.

Laviola, G., Adriani, W., Terranova, M. L., and Gerra, G. (1999). Psychobiological risk factors for vulnerability to psychostimulants in human adolescents and animal models. Neurosci. Biobehav. Rev. 23, 993-1010.

Levine, S. (2001). Primary social relationships influence the development of the hypothalamic-pituitary-adrenal axis in the rat. Physiol. Behav. 73, 255-260.

Lewin, J., Schmitt, A. O., Adorjan, P., Hildmann, T., and Piepenbrock, C. (2004). Quantitative DNA methylation analysis based on four-dye trace data from direct sequencing of PCR amplifications. Bioinformatics 20, 3005-3012.

Lynch, W. J., and Carroll, M.E. (1999). Sex differences in the acquisition of intra- venously self-administered cocaine and heroin in rats. Psychopharmacology (Berl.) 144, 77-82.

McCabe, S. E., Teter, C. J., Boyd, C. J., Knight, J. R., and Wechsler, H. (2005) Nonmedical use of prescription opioids among U.S. college students: prevalence and correlates from a national survey. Addict. Behav. 30, 879-805.

McCormick, C. M., Linkroum, W., Sallinen, B. J., and Miller, N.W. (2002) Peripheral and central sex steroids have differential effects on the HPA axis of male and female rats. Stress 5 , 235-247.

McGaugh, J. L. (2000). Memory - a century of consolidation. Science 287 248-251.

McHugh, S. B., Deacon, R. M., Rawlins, H. N., and Bannerman, D. M. (2004). Amygdala and ventral hippocampus contribute differentially to mechanisms of fear and anxiety. Behav Neurosci. 118, 63-78.

Meaney, M. J. (2001). Maternal care, gene expression, and the transmission of individual differences in stress reactivity across generations. Annu. Rev Neurosci. 24, 1161-1192.

Moles, A., Kieffer, B. L., and D'amato, F. R. (2004). Deficit in attachment behavior in mice lacking the mu-opioid receptor gene. Science 304, 1983-1986.

Moore, C. L., and Chadwick-Dias, A. M. (1986). Behavioral responses of infant rats to maternal licking: variations with age and sex. Dev. Psychobiol. 19, 427-438.

Moore, C. L., and Morelli, G. A. (1979). Mother rats interact differently with male and female offspring. J. Comp Physiol. Psychol. 93, 667-684.

Nelson, E. E., and Panksepp, J. (1998). Brain substrates of infant-mother attachment: contributions of opioids, oxytocin, and norepinephrine. Neurosci. Biobehav. Rev. 22, 437-452.

Nielsen, D. A., Yuferov, V., Hamon, S., Jackson, C., Ho, A., Ott, J., and Kreek, M. J. (2009). Increased OPRM1 DNA methylation in lymphocytes of methadone-maintained former heroin addicts. Neuropsychopharmacology 34, 867-873.

Razin, A. (1998). CpG methylation, chromatin structure and gene silencing-a three-way connection. EMBO J. 17, 4905-4908.

Rice, D., and Barone, S. (2000). Critical periods of vulnerability for the developing nervous system: evidence from human and animal models. Environ. Health Perspect. 108, 511-533.

Richmond, G., and Sachs, B. D. (1984). Maternal discrimination of pup sex in rats. Dev. Psychobiol. 17, 87-89.

Rivier, C. L., and Plotsky, P. M. (1986). Mediation by corticotropin releasing factor (CRF) of adrenohypophysial hormone secretion. Annu. Rev. Physiol. 48, 475-494.

Roth, T. L., Lubin, F. D., Funk, A. J., and Sweatt, J.D. (2009). Lasting epigenetic influence of early-life adversity on the BDNF gene. Biol. Psychiatry 65, 760-769.

Sapolsky, R. M., and Meaney, M. J. (1986). Maturation of the adrenocortical stress response: neuroendocrine control mechanisms and the stress hyporesponsive period. Brain Res. Rev. 11, 65-76.

Schug, J., and Overton, G. C. (1977). TESS: Transcription Element Search Software on the WWW. [http://www. cbil.upenn.edu/cgi-bin/tess/tess]. University of Pennsylvania. [accessed February 7, 2011]

Scoville, W. B., and Milner, B. (1957). Loss of recent memory after bilateral hippocampal lesions. J. Neurol. Neurosurg. Psychiatr. 20, 11-21.

Sinha, R. (2001). How does stress increase risk of drug abuse and relapse? Psychopharmacology 158, 343-359.

Stanton, M. E., Gutierrez, Y. R., and Levine, S. (1988). Maternal deprivation potentiates pituitary-adrenal stress responses in infant rats. Behav. Neurosci. 102, 692-700.

Stewart, J., Woodside, B., and Shaham, Y. (1996). Ovarian hormones do not affect the initiation and maintenance of intravenous self-administration of heroin in the female rat. Psychobiology 24, 154-159.

Suchecki, D., Nelson, D. Y., Vanoers, H., and Levine, S. (1995). Activation and inhibition of the hypothalamicpituitary-adrenal axis of the neonatal rat: effects of maternal deprivation. Psychoneuroendocrinology20,169-182.

Swiss, V. A., and Casaccia, P. (2010). Cellcontext specific role of the E2F/Rb pathway in development and disease. Glia 58, 377-390.

Viau, V., and Meaney, M. J. (1991). Variations in the hypothalamicpituitary-adrenal response to stress during the estrous cycle in the rat. Endocrinology 129, 2503-2511.

Vigod, S. N., and Stewart, D. E. (2009). Emergent research in the cause of mental illness in women across the lifespan. Curr Opin Psychiatry 22, 396-400.

Vucetic, Z., Kimmel, J., and Reyes, T. M. (2011). Chronic high-fat diet drives postnatal epigenetic regulation of $\mu$-opioid receptor in brain. Neuropsychopharmacology 36, 1199-1206.

Vucetic, Z., Kimmel, J., Totoki, K., Hollenbeck, E., and Reyes, T. M. (2010). Maternal high-fat diet alters methylation and gene expression of dopamine and opioid-related genes. Endocrinology 151, 4756-4764. 
Way, B. M., Taylor, S. E., and Eisenberger, N. I. (2009). Variation in the m-opioid receptor gene (OPRM1) is associated with dispositional and neural sensitivity to social rejection. Proc. Natl. Acad. Sci. U.S.A. 106, 15079-15084.

Weaver, I. C., Cervoni, N., Champagne, F. A., D'alessio, A. C., Sharma, S., Seckl, J. R., Dymov, S., Szyf, M., and Meaney, M.J. (2004). Epigenetic programming by maternal behavior. Nat. Neurosci. 7, 847-854.
Winslow, J. T., and Insel, T. R. (1991). Endogenous opioids: do they modulate the rat pup's response to social isolation? Behav. Neurosci. 105, 253-263.

Zubieta, J.-K., Dannals, R. F., and Frost, J. J. (1999). Gender and age influences on human brain mu-opioid receptor binding measured by PET. Am. J. Psychiatry 156, 842-848.

Conflict of Interest Statement: The authors declare that the research was conducted in the absence of any commercial or financial relationships that could be construed as a potential conflict of interest.

Received: 22 February 2011; accepted: 12 April 2011; published online: 03 May 2011. Citation: Hao Y, Huang W, Nielsen DA and Kosten TA (2011) Litter gender composition and sex affect maternal behavior and DNA methylation levels of the Oprm 1 gene in rat offspring. Front. Psychiatry 2:21. doi: 10.3389/fpsyt.2011.00021
This article was submitted to Frontiers in Child and Neurodevelopmental Psychiatry, a specialty of Frontiers in Psychiatry.

Copyright $\odot 2011$ Hao, Huang, Nielsen and Kosten. This is an open-access article subject to a non-exclusive license between the authors and Frontiers MediaSA, which permits use, distribution and reproduction in other forums, provided the original authors and source are credited and other Frontiers conditions are complied with. 